УДК 330.1

Т. В. Огородникова

Байкальский государственный университет, г. Иркутск, Российккая Федерация

\title{
НЕЛИНЕЙНЫЕ ВОЛНОВЫЕ ПРЕДСТАВЛЕНИЯ В ОРТОДОКСАЛЬНОЙ ЭКОНОМИЧЕСКОЙ ТЕОРИИ
}

\begin{abstract}
АНнотАция. В статье представлен обзор, обобщающий первоначальные предпосылки и достижения в области внедрения в экономическую теорию методологии и инструментария современной физической концепции нелинейных волн. Выявляются и структурируются отдельные представления, понятия, логические умозаключения о нелинейных волновых механизмах, содержащиеся в работах представителей различных экономических школ XIX-XX вв. Рассматриваются основные направления традиционных экономических исследований в свете теории нелинейных волн. Соблюдая общепринятую классификацию наиболее значительных теорий фундаментальной экономической науки, автор показывает, какое место в этих концепциях отводилось таким основополагающим категориям нелинейной волновой теории, как волна, колебания, среда, механизм возникновения и распространения колебаний и волн, динамика, нелинейность. Анализируются экономический смысл, предписываемый этим понятиям, а также степень использования соответствующего математического аппарата.

кЛючЕВЫЕ словА. Нелинейная волна; экономическая динамика; экономические колебания; цикличность.

ИНФОРМАЦИЯ О СТАТЬЕ. Дата поступления 11 апреля 2016 г.; дата принятия к печати 29 апреля 2016 г.; дата онлайн-размещения 31 мая 2016 г.
\end{abstract}

T. V. Ogorodnikova

Baikal State University,

Irkutsk, Russian Federation

\section{NON-LINEAR WAVE PRESENTATION IN ORTHODOX ECONOMIC THEORY}

ABSTRACT. The article presents a review that generalizes the initial prerequisites and achievements in the field of introduction of methodology and instrumentarium of modern physical concept of the non-linear waves into the economic theory. It identifies and structures separate presentations, concepts, logical phylosophics about the non-liner wave mechanisms containing in works of representatives of various economic schools $\mathrm{XIX}-\mathrm{XX}$ centuries. It considers main directions of traditional economic investigations in terms of the non-linear waves theory. While keeping up the classifications of the most significant theories of fundamental economic science, the author shows what place in these concepts is featured to such essential categories of the non-linear waves theory as wave, oscillations, mechanism of occurring and distribution of waves, non-linearity. It analyses the economic sense bound over to these concepts. as well as the degree of using the corresponding mathematical apparatus.

KEYWORDS. Non-linear wave; economic dynamics; economic oscillations; cyclicity. ARTICLE INFO. Received April 11, 2016; accepted April 29, 2016; available online May 31, 2016.

В XXI в. очевидную популярность приобрела идея о привнесении в самые разнообразные сферы научного знания методологии и инструментализма физической теории волн, в частности, нелинейных. Особенно активно заинтересовались возможностями описания с этих позиций различных феноменов представители гуманитарных наук: социологи, историки и т. д.

(C) T. В. Огородникова, 2016

\section{Baikal Research Journal}


Однако, на наш взгляд, в наибольшей степени «волновая философия» продуктивна для создания теорий эконолического поведения субъектов и систем: микро-, мезо- и макроуровней исследования. Эта тенденция представляется совершенно естественной, если объективно оценить прогностические возможности таких современных научных концепций, как нелинейная экономическая динамика, синергетика, цикломатика и, наконец, солитоника.

Следует отметить, что определенное движение в этом направлении имеет место быть в настоящее время. Однако вряд ли можно считать, что волновые представления о природе экономических явлений существенно скорректировали вектор развития экономической теории, как методологической основы прикладных экономических знаний. В этом смысле более плодотворным представляется говорить об отдельных элементах, чертах или предпосылках волновой теории, встречающихся в фундаментальных экономических исследованиях.

Не нарушая хронологии и традиционной классификации, отражающей наиболее значительные направления экономической мысли, попытаемся показать, какое место в этих концепциях отводилось таким основополагающим понятиям нелинейной волновой теории, как «колебания», «волна», «динамика», «нелинейность». Обратим внимание на то, какой экономический смысл им предписывался, какие возможности использования соответствующего математического аппарата были реализованы.

Обзор предварим некоторыми общими замечаниями. Термин «волна» не является широко распространенным в современной экономической теории, хотя факт наличия колебательной динамики экономических систем можно считать вполне признанным ею. Еще в 1934 г. известный исследователь так называемых «больших циклов конъюнктуры» Н. Д. Кондратьев отмечал, что «волнообразно-циклический" [1, с. 24] характер капиталистической экономики не вызывает сомнения. Образом волнового восприятия в экономике стали разнообразные экономические циклы. «Волна» ассоциировалась с синусоидальной траекторией, по которой изменяются реальные и денежные параметры макроэкономической системы. Как видим, такой подход далек от понимания сути волновой динамики. Практически все авторы использовали термин «волна» лишь в качестве синонима понятий «цикл», или «колебание». Собственного смыслового значения этому термину в экономике не предписывалось. Следует отметить, что даже методологически противоположные теоретические концепции в вопросах волновой терминологии демонстрируют единство: трактуют волну исключительно как "образ» динамики, а не как способ передачи импульсов между элементами экономической среды.

Нелинейность, как математическое свойство, присутствовала во многих моделях, созданных, главным образом в XX в. Так, к числу нелинейных динамических экономических моделей относят модель паутинообразного механизма ценового реагирования, модель оптимального роста, модель с перекрывающимися поколениями, кейнсианские модели бизнес-циклов, модели циклов экономического роста Калдора и Гудвина, модель роста Солоу, модель спроса с адаптивными предпочтениями, мальтусианскую и неоклассическую демографические модели, модели с финансовой обратной связью, модели выбора с эндогенными вкусами, модели роста производительности, модели дуополий и др. Интересно, что классические модели общего равновесия со стандартным предположением о совершенной конкуренции, совершенном предвидении и совершенной информации тоже могли воспроизводить нетрадиционные колебания [2, с. 85].

Однако «философия нелинейности», т. е. представление о том, что динамика экономических систем есть в большинстве случаев стохастический сложный, взаимообусловленный процесс, проникает в экономический анализ только с конца $\mathrm{XX}$ столетия в контексте развития таких междисциплинарных направлений на-

\section{Baikal Research Journal}

электронный научный журнал Байкальского государственного университета 
учного знания, как синергетика и эконофизика. Именно в это время оформилось актуальное и перспективное направление экономической теории - «нелинейная экономическая динамика», которая сосредоточивается главным образом на диагностике сложного поведения, элементов хаоса, неустойчивостей, автоколебаний в популярных макроэкономических моделях. Однако следует отметить, что проблема устойчивости нелинейного волнового процесса, в частности солитонообразования, в экономических системах пока не получила должного осмысления и развития.

В свете данных замечаний очевидно, что описать эволюцию нелинейной волновой теории в экономике не представляется возможным за неимением таковой. Цель нашего обзора заключается в том, чтобы выявить и структурировать отдельные представления, понятия, логические умозаключения о нелинейных волновых механизмах, содержащиеся в работах представителей различных экономических школ и направлений.

Итак, сосредоточимся на анализе того, какое отражение в экономической теории получили идеи, связанные с такими понятиями, как волна, колебания, среда, механизм возникновения и распространения колебаний и волн, динамика, нелинейность.

Микроэкономическая теория никогда не оперировала понятием «волна», не рассматривала волновой процесс ни как форму поведения микросубъектов, ни как процесс передачи экономических импульсов между ними, ни как форму протекания процессов на рынках отдельных продуктов. Статичность и строгая линейность микроэкономического анализа не позволила увидеть в поведении потребителей, фирм, рынков источников волновых процессов. Хотя колебания внутри такой микроэкономической системы, как рынок отдельного продукта, были идентифицированы.

Едва ли не единственной моделью, где колебания составляют основу анализа, является известная "паутинообразная» модель рынка Тинбергена. Описанные им колебания имели, безусловно, линейный характер и по своей природе принимали форму так называемого «нащупывания» параметров. Источником флуктуаций в системе «рынок отдельного продукта» в данной модели выступает временной лаг запаздывания. Обратим внимание на то, что эта модель оперирует понятием «устойчивость» применительно к колебательному процессу. Однако этот термин используется исключительно для того, чтобы обозначить факт постоянства, неизменности периодических движений параметров исследуемой экономической системы.

Возникновение и развитие макроэкономической науки в XX столетии, обилие фактических данных о флуктуациях параметров макроэкономических систем предопределило научный интерес к концепциям колебаний и механизму их распространения. В это время в экономической теории стал упоминаться термин «волна» для обозначения некоего периодического движения количественных характеристик макроэкономики.

Одно из первых упоминаний о волнах в экономике относится к еще более раннему периоду (середине XIX столетия) и принадлежит Д. Лэнгтону, который в статье, опубликованной в Трудах Манчестерского статистического общества (1857), не только говорит о периодичности в состояниях экономики, но и рассматривает экономические потрясения как явления, имеющие волнообразное движение. Он говорит: «Эти потрясения сопутствуют иной волне, повторяющейся, по-видимому, через каждые десять лет, и в образовании которой причины морального (то есть психологического) порядка играют несомненную роль. Движущая причина этих конвульсивных движений заключена, по-видимому, в неумеренном использовании кредита» [3].

Обратим внимание на формулировку, в которой присутствуют все традиционные признаки неадекватного использования в экономической теории понятия волны, которые мы можем наблюдать далее, вплоть до настоящего времени. У Д. Лэнгтона

\section{Baikal Research Journal}


волна - лишь форма линейного «конвульсивного» движения экономики, заданного внешними импульсами (неумеренным пользованием кредитом).

Вплоть до осознания научным миром факта цикличности рыночной экономики интерес к феномену колебаний экономической конъюнктуры обусловливался наличием лишь кризисных явлений. Эта тенденция впервые была озвучена В. Зомбартом, который в начале $90-\mathrm{x}$ гг. ХIX столетия высказал мысль о том, что теория кризисов должна превратиться в более общую теорию колебаний конъюнктуры в целом. Таким образом, лишь с этого времени колебательные процессы в экономике стали описывать в виде явлений, имеющих волнообразную траекторию.

В работах, относящихся к «доциклической эпохе» в экономической теории, мы можем проследить только за трактовками источника импульсного воздействия, провоцирующего вынужденное затухающее движение в экономической системе, результатом которого становится экономический кризис. Прокомментируем лишь некоторые из этих подходов:

1. Дж. Милльс (1867) выделяет так называемый «кредитный цикл», источник которого заключен в «моральных причинах»: «болезнь торговых кризисов - это явление, причина которого лежит, по существу, не в кошельке, а в душе» [3, с. 12]. Причина кризиса, по его мнению, не столько в свойствах экономических институтов, сколько в заблуждениях психологического порядка, присущих мышлению хозяйствующих лиц. Благоприятные условия порождают оптимизм, оптимизм - безрассудство, безрассудство - стагнацию.

2. А. Маршалл (1890) называет «безрассудное расширение кредита» источником движения экономики к кризису [4]. Депрессия, следующая за кризисом, рассматривается им как состояние дезорганизации в области торговли.

3. Г. Джорж (1879) выделяет так называемую «промышленную депрессию»; причина - спекуляция землей. Соответственно, предлагаемый им метод подавления негативного действия этого источника - установление налога на земельную ренту.

Анализируя предысторию теории циклических колебаний экономики, следует отметить постепенное изменение терминологии - «замирающая торговля», «торговые кризисы», «периодические кризисы», «кредитный цикл», «промышленная депрессия» и, наконец, «инвестиционный цикл». Смена этих терминов отражает собой эволюционные процессы в рыночной экономике, растущее понимание существенной природы колебаний в экономической жизни, явлений роста и в особенности процесса капиталообразования и процесса сбережения и инвестирования. Именно эти последние идеи выдвинулись на первый план в ходе развития теории экономического цикла в XX в.

Приоритет в создании комплексных циклических представлений о характере рыночной экономики принадлежит К. Викселю (1898) и М. И. Туган-Барановскому (1901). Именно с работ этих авторов начинается систематические исследования форм и механизмов существования экономических систем, которые рассматривались как аналог волнового процесса. В этой связи необходимо вновь подчеркнуть, что сложившийся в рамках ортодоксальной экономической теории подход к описанию экономических циклов не рассматривает последние как волновой процесс в подлинном смысле, поскольку не отражает механизм передачи энергетических импульсов внутри однородной экономической системы. Целесообразнее говорить не о волнах конъюнктуры, или деловой активности, а о флуктуациях әконолических данных. Основная методологическая проблема при этом заключается в определении источника - осииллятора этих периодических колебаний.

Весьма значительный спектр характеристик, по которым различают экономические флуктуации (амплитуда, область распространения, длительность, географи-

\section{Baikal Research Journal}

электронный научный журнал Байкальского государственного университета 
ческая принадлежность, степень устойчивости, соответствие тенденции долгосрочной динамики и т. д.) стал основой множества классификаций циклов.

В середине XX столетия появилась наиболее популярное деление теорий циклов на экзогенные и эндогенные. В рамках такой классификации для объяснения экономических флуктуаций были предложены две причины: осциллятор цикла располагается вне системы (экзогенные теории циклов), и осциллятор формируется внутри системы, как результат сложных взаимодействий между элементами, или уровнями системы (эндогенные теории циклов). При этом в эндогенных концепциях рассматривался также вопрос о механизме функционирования осциллятора: имеет ли он собственные колебания, и поэтому приводит в колебательное движение всю экономическую систему, или ее флуктуации обусловливаются лишь фактом его наличия и структурными особенностями самой системы. В этой классификации выделяются также смешанные теории (полуэндогенные), которые берут эндогенные факторы за основу только для объяснения одной точки поворота - кризиса и депрессии. Согласно этим теориям каждое циклическое движение прекращается, и остановка длится до тех пор, пока, наконец, экзогенные факторы не дадут начало новому оживлению. Каждый цикл рассматривается здесь как обособленная сущность.

Экзогенные модели колебаний экономических систем относятся к числу самых ранних и простых. Хронологически они создавались еще до эпохи распространения нелинейных динамических методов и основывались на постулировании механизма цикла, поддерживающегося беспрестанно чередующимися «внешними» нарушениями, задающими ритм флуктуациям параметров системы.

В 30-40-х гг. ХХ столетия наблюдалось резкое увеличение числа формальных моделей эндогенных циклов, в которых использовались различные модификации версий акселератора инвестиций и мультипликатора потребления (Р. Харрод, М. Калецкий, П. Самуэльсон, Л. Метцлер, Дж. Хикс). Н. Калдор (1940) и Р. Гудвин (1955) стали, пожалуй, наиболее выдающимися учеными в этой сфере, а их труды - наиболее часто цитируемыми. Предложенные модели, которые многие считают прототипами нелинейных динамических систем в экономике, генерируют динамику на базе эффекта мультипликатора-акселератора с нелинейной функцией инвестиций.

Нетрудно заметить, что мультипликативно-акселераторные взаимоотношения, разворачивающиеся внутри экономической системы, являются моделью подлинно волнового процесса, т. е. мультипликатор и акселератор по существу играют роль индикаторов наличия волнового процесса, поскольку эти механизмы описывают процесс передачи колебательных импульсов между элементами системы. При этом конкретная форма первоначального импульса, приводящего в движение механизм мультипликатора-акселератора для процесса образования волны, не существенна. Волновой процесс можно диагностировать по характерным внешним и внутренним признакам в случае действия любого мультипликатора: и инвестиционного, и мультипликатора государственных расходов, и налогового, и денежного. Однако несмотря на прозрачность и очевидность наличия волновых процессов в этих моделях, традиционная экономическая теория не отождествила мультипликативно-акселерационный механизм с механической волной макроэкономических взаимодействий.

$\mathrm{B}$ первой половине $\mathrm{XX}$ столетия оформилась концепция долговременных циклов конъюнктуры. Именно эти циклы, единственные из всего многообразия экономических циклов, с легкой руки их главного идеолога Н. Кондратьева, были названы волнали (длинными). В этой связи следует отметить, что термин «волна» в экономической теории применяется исключительно в отношении долгосрочных колебаний рыночной конъюнктуры.

Анализируя работы в области концепции длинных волн в экономике в целом, можно сделать вывод, что термин «волна» употреблялся авторами исключитель-

\section{Baikal Research Journal}

электронный научный журнал Байкальского государственного университета 
но для того, чтобы выделить и подчеркнуть какую-то особую форму проявления этих колебаний в экономике, а именно: длительность, плавность, непрерывность. Длинная волна в их понимании - это некая форма глобального движения мировых экономических процессов. Так, ключ к кондратьевскому пониманию волн в экономике можно увидеть, например, в его выводах о результатах изучения временных рядов натуральных и денежных параметров национальной экономики. Он отмечает: «Динамика изученных элементов показала наличие больших циклов. В отношении тех элементов, динамика которых такую тенденцию не обнаруживает, циклы эти проявляются в волнообразной смене телпа развития этой тенденции (курсив наш. - T. O.)» $[1$, с. 44]. Обратим внимание на то, что речь идет об ускорении или заледлении в темпах изменения конъюнктуры. По существу, это вторая производная функции любого реального или денежного показателя по времени. Такая постановка еще раз убеждает нас в том, что волна для Н. Кондратьева - лишь геометрическая форма тренда, по которому эволюционирует конкретный экономический показатель при прочих равных условиях (это допущение - ключевое). В то же время Н. Кондратьев не отождествляет волну с циклом. Так, в частности, он отмечает: «Очевидно, что если доступный нашему изучению отрезок времени и достаточен, чтобы решить вопрос о существовании больших волн конъюнктуры, то он недостаточен, чтобы с полной категоричностью признать и цикличность этих волн (курсив наш. - T. O.)» [1, с. 61]. Другими словами, цикличность он понимает как периодическое повторение событий, в рассмотренном им случае - периодическое повторение волновой формы динамики основных экономических показателей.

В целом, создается впечатление, что термин «волна» используется создателями концепции «длинных волн» исключительно для «удобства», для того, чтобы обособить свою позицию от многочисленных исследований в области циклических колебаний и, возможно, подчеркнуть ее глобальную ориентацию и всеохватность, обозначить отличие долговременных тенденций от «частных" циклических колебательных движений в экономике. Подлинная сущность волнового механизма, как формы передачи экономических импульсов между элементами системы, в этих концепциях остается нераскрытой.

Гипотеза о длинных волнах в экономике также не дает нам шансов увидеть не линейный характер этих долговременных флуктуаций. Хотя тот же Н. Кондратьев, например, отмечал, что «динамика экономической жизни при капиталистическом строе общества имеет не простой и линейный, а сложный и циклический характер» [Там же, с. 24]. При этом, как видим, линейности противопоставляется иикличность, а не нелинейность. Таким образом, сложность поведения системы он видит в том, что траектория динамики экономической конъюнктуры развивается не по прямой линии, а по синусоиде. Это еще очень далеко от осознания подлинно сложного, нелинейного экономического поведения.

Прочие концепции «длинных волн», в разработке которых принимали участие такие авторы, как Й. Шумпетер (осциллятор долговременных флуктуаций — технические новшества и усовершенствования, а также связанное с ними освоение новых ресурсов и территорий), В. Войтинский, Г. Кассель, Д. Уоррен, У. Пирсон (причина долговременных колебаний - в сфере денежного обращения), С. Кирьяси-Вантруп, К. Виксель (причина «больших» колебаний - государственные и военные расходы) учитывали нелинейность в качестве математического свойства модели. Однако это не помешало авторам постулировать одно из основных свойств, предписываемое «длинной волне», согласно которому параметры малого цикла имеют тенденцию увеличиваться по абсолютным размерам, интенсивности и продолжительности в случае совпадения его с аналогичной тенденцией, соответству-

\section{Baikal Research Journal}

электронный научный журнал Байкальского государственного университета 
ющей большому циклу, и наоборот. Отметим, что такая особенность соответствует только линейному восприятию диналики экономической систелы, при соблюдении которого совокупная амплитуда колебаний в рамках малого цикла стимулируется, или угнетается соответствующей тенденцией в большом цикле. Проще говоря, речь идет о простом суммировании амплитуд колебаний плоских волн. Это исключительно линейный суперпозиционный подход, не применимый для описания более сложных взаимодействий.

Что касается прочих направлений традиционной экономической теории, в которых не уделялось столь пристального внимания исследованию природы колебательной экономической динамики, как кейнсианские и неокейнсианские, то среди них можно упомянуть монетаристское направление, экономику предложения, неоавстрийцев.

Так, в частности, идеологи монетаристской концепции оперируют понятием «волна» в таком же контексте, что и их «оппоненты» - кейнсианцы. А именно: исключительно для обозначения регулярности параметрических колебаний экономической системы. Отличительной особенностью монетаристской концепции цикла является, как известно, идея о денежной природе осциллятора.

Сторонники «supply — side economics» (экономики предложения) (Ф. фон Хайек) специальных исследований экономических колебаний не проводили. Хотя вся идеология этого направления экономической мысли, а главное аргументация в пользу «спонтанного рыночного порядка» и сведения функций государства к обеспечению условий его бесперебойной работы, строится на анализе колебательных движений экономической системы, сопровождающихся типичными экономическими проблемами (неуправляемой инфляцией, высокой безработицей, низкой динамикой воспроизводства и т. д.). Их рекомендации касаются не того, как «сгладить» циклические колебания, имманентные экономической системе, а того, как принципиально избежать этих экономических проблем. Таким образом, предмет исследования сапплайсайдеров в области колебательной экономической динамики составляет механизм возникновения негативных социально-экономических явлений (инфляции, безработицы), а не механизм развертывания колебательного процесса в экономике. В этом смысле можно сказать, что данная концепция вернулась к идеям «доциклического» периода в истории экономической мысли.

Тем не менее, они выстраивают собственные цепочки взаимозависимостей элементов экономической системы, имеющие своим результатом инфляцию, или безработицу, т. е. по существу, воспроизводят идеологию передачи волновых импульсов, исходящих от какого-то источника (чаще всего источником выступают действия государственных органов, осуществляющих конкретные мероприятия экономической и социальной политики). Так, в частности, механизм возникновения безработицы в интерпретации теоретиков экономики предложения приводится в движение импульсом, исходящим из системы государственного социального обеспечения. При этом они выделяют две волны, усиливающие друг друга, т. е. построенные на реализации линейного принципа суперпозиции. Первая волна такова: активные социальные программы приводят в движение (ведут к уменьшению) стимулы к поиску работы у незанятых, это в свою очередь ведет к повышению "естественной» нормы безработицы. На эту волну накладывается другая, исходящая также от государства, но инициированная необходимостью повышать объемы налогообложения для того, чтобы финансировать эти социальные программы. Далее приходит в движение уровень реальных доходов (отклоняется от значения, характерного, для свободного рынка труда). Это отклонение в свою очередь стимулирует добровольный переход людей в разряд безработных (эффект замены). Суммарное действие этих цепочек взаимозависимостей имеет результатом усиленный рост безработицы.

\section{Baikal Research Journal}


У новых классиков (Р. Лукас, Т. Сарджент, Н. Уоллес, Э. Прескот, Р. Барроу) есть два варианта ответов на вопрос об источнике экономических флуктуаций. Первый получил название теории несовершенной информации, а второй известен как теория реального бизнес-цикла.

В первой теории (теории несовершенной информации) прослеживается такая логика возбуждения колебательных движений эконолической систелы: инфляция (феномен денежного сектора экономики) - двойственная оценка ее со стороны предпринимателя - расширение производства собственного продукта - экономический подъем в системе в целом.

Внедрение нелинейности привело к возникновению современной теории реального цикла деловой активности, в рамках которой динамика экономических переменных возникает как решение задачи оптимизации во времени. При этом считается, что экзогенные шоки вводятся в такие модели для описания отдельных интересующих нас внешних воздействий, а отмеченные характеристики возникают внутри таких нелинейных моделей вне зависимости от экзогенных факторов.

Особое место среди современных макроэкономических теорий занимают «новые австрийцы», продолжающие традицию известной в начале прошлого века австрийской школы. Ни термина «волна», ни термина «колебания» в трудах ее основоположников мы не встретим. Индивидуализм, субъективизм экономического поведения, как основа мировоззрения представителей этой школы, предопределили отрицание ими каких-либо периодических закономерностей [5-17].

В целом, среди всех наиболее известных научных школ и направлений традиционной экономической теории самый активный интерес к рассмотрению механизмов колебательных процессов в экономических системах проявили сторонники активной государственной политики. Видимо для того, чтобы утвердить необходимость целенаправленного воздействия государства на функционирование экономической системы, которой объективно имманентны колебания с их негативными проявлениями. Красноречивый тезис в пользу этой идеи можно увидеть у Э. Хансена: «Нельзя, поэтому, рассматривать цикл как патологическое состояние. Он присущ природе современной динамической экономики. «Встроенные» институциональные механизмы могут, конечно, сузить пределы колебаний, но лишь в некоторой мере. Необходима положительная антициклическая программа» [3, с. 306].

Общие выводы, касающиеся разработки концепции нелинейной волновой динамики в ортодоксальной экономической теории XX в:

Термин «волна» трактовался исключительно с позиций параметрических, или вынужденных циклических колебаний экономической конъюнктуры, без описания и анализа механизма развертывания волнового процесса в основном для идентификации синусоидальной формы траектории параметров макроэкономической системы.

Большинство формальных макроэкономических моделей являлись нелинейными по форме. Однако, по сути, макроэкономическая динамика рассматривалась как симметричный линейный процесс, строящийся по принципу суперпозиции. Фундаментальные свойства нелинейных систем, в частности стохастичность, не диагностировались.

В завершение следует отметить, что, столь скудные достижения ортодоксальной экономической теории в области внедрения методологии и инструментализма теории нелинейных волн вполне объективны: традиционная экономическая теория все-таки исторически создавалась в конце XIX - первой половине XX в. И если в это время теория волн, восходящая еще от идей Архимеда, была достаточно развита, то нелинейная волновая динамика, особенно в категориях устойчивости или

\section{Baikal Research Journal}

электронный научный журнал Байкальского государственного университета 
неустойчивости, завладела умами физиков и математиков лишь во второй половине XX столетия. Тем более интересным было увидеть ее предпосылки в ортодоксальной экономической науке. Впоследствии многие из классических микро- и макромоделей стали базовыми для нахождения в них нелинейностей, хаоса и источников автоволновых процессов.

\section{Список использованной литературы}

1. Кондратьев Н. Д. Избранные сочинения / Н. Д. Кондратьев. - М. : Экономика, 1993. $-541 \mathrm{c}$.

2. Прохоров А. Нелинейная динамика и теория хаоса в экономической науке: историческая ретроспектива / А. Прохоров // Квантиль. - 2008. — № 4. - С. 79-92.

3. Классики кейнсианства : в 2 т. / Р. Харрод, Э. Хансен [и др.] ; сост. А. Г. Худокормов. - М. : Экономика, 1997. - Т. 2. - 431 с.

4. Маршалл А. Принципы экономической науки : в 3 ч. : пер. с англ. / А. Маршалл. М. : Прогресс, 1993. — Т. 1. - 594 с.

5. Блауг М. Методология экономической науки, или как экономисты объясняют : пер. с англ. / М. Блауг ; под науч. ред. В. С. Автономова. - М. : НП ЗЖурнал «Вопросы экономики», 2004. $-416 \mathrm{c}$.

6. Классики кейнсианства : в 2 т. / Р. Харрод, Э. Хансен [и др.] ; сост. А. Г. Худокормов. - М. : Экономика, 1997. - Т. 1. - 416 с.

7. Мизес Л., фон. Теория и история: Интерпретация социально-экономической эволюции : пер. с англ. / Людвиг фон Мизес ; под ред. А. Г. Грязновой. - М. : Юнити-Дана, 2001. 295 c.

8. Некипелов А. Приоритеты развития современной экономической теории / А. Некипелов, А. Татаркин, Е. Попов //Экономическая наука современной России. — 2006. - № 3. C. 127-140.

9. Румянцева С. Ю. Эволюционная теория и экономическая динамика / С. Ю. Румянцев // Проблемы современной экономики. - 2015. — № 1 (53). - С. 67-71.

10. Фахрутдинова Е. Проблемы методологии в развитии и модернизации экономики / Е. Фахрутдинова, С. Мокичев // Экономические науки. - 2015. - № 1 (122). - С. 11-14.

11. Фахрутдинова Е. Формирование и развитие новой концепции в методологии экономической теории / Е. Фахрутдинова, С. Мокичев // Экономические науки. - 2013. № 6 (103). - С. 29-33.

12. Шумпетер Й. История экономического анализа : пер. с англ. : в 3 т. / Й. Шумпетер ; под ред. В. С. Автономова. - СПб. : Экон. шк., 2001.

13. Эггертсон Т. Экономическое поведение и институты : пер. с англ. / Т. Эггертсон. М. : Дело, 2001. -408 с.

14. Kirman A. The Intrinsic Limits of Modern Economic Theory: The Emperor Has No Clothes / A. Kirman // Economic Journal. — 1989. — Vol. 99, № 395. — P. 126-139.

15. Lowson T. A Realist Perspective on Contemporary «Economic Theory» / T. A Lowson // Journal of Economic Issues. - 1995. - Vol. 29, № 1. - P. 1-32.

16. Nort D. C. Five propositions about Institutional Change / D. C. Nort // Explaining Social Institutions / ed. by J. Knight, I. Sened. - University of Michigan Press, 1995. — P. 15-26.

17. Solow R. Economics: Is Something Missing? / R. Solow // Economic History and the Modern Economist. — Oxford : Basil Blackwell, 1986. — P. 24-25.

\section{References}

1. Kondratyev N. D. Izbrannye sochineniya [The Selected Works]. Moscow, Ekonomika Publ., 1993. $541 \mathrm{p}$.

2. Prokhorov A. Noh-linear dynamics and chaos theory in economics: a historical prospect. Kvantil' = Guantile, 2008, no. 4 2008, no. 4, pp. 79-92. (In Russian).

3. Kharrod R., Khansen E. et al.; Khudokormov A. G. (ed.). Klassiki keinsianstva [Classics of Keynesianism]. Moscow, Ekonomika Publ., 1997. Vol. 2. 431 p.

4. Marshall Alfred. Principles of Political Economy. London, New York, MacMillan \& Co., 1890. Vol. I. 754 p. (Russ. ed.: Marshall A. Printsipy politicheskoi ekonomii. Moscow, Progress Publ., 1993. Vol. 1. 594 p.).

\section{Baikal Research Journal}


5. Blaug Mark. The Methodology of Economics, or How Economists Explain. Cambridge University Press, 1992.370 p. (Russ. ed.: Blaug Mark, Avtonomov V. S. (ed.). Metodologiya ekonomicheskoi nauki, ili kak ekonomisty ob"yasnyayut [Methodology of economics, or how economists explain]. Moscow, NP «Journal of Economic Issues » Publ., 2004. 416 p.).

6. Kharrod R., Khansen E. et al.; Khudokormov A. G. (ed.). Klassiki keinsianstva [Classics of Keynesianism]. Moscow, Ekonomika Publ., 1997. Vol. 1. 416 p.

7. Mises Ludvig von. Theory and History: An interpretation of Social and Economic Evolution. Auburn, Ludwig von Mises Institute, 1985. (Russ. ed.: Mises Ludvig von. Teoriya i istoriya: Interpretatsiya sotsial'no-ekonomicheskoi evolyutsii. Moscow, Yuniti-Dana Publ., 2001. 295 p.).

8. Nekipelov A., Tatarkin A., Popov E. Priorities in developing modern economic theory. Ekonomicheskaya nauka sovremennoi Rossii = Economic Science of Modern Russia, 2006, no. 3, pp. 127-140. (In Russian).

9. Rumyantseva S. Yu. Evolutionary theory and economic dynamics. Problemy sovremennoi ekonomiki = Problems of Modern Economy, 2015, no. 1 (53), pp. 67-71. (In Russian).

10. Fakhrutdinova E., Mokichev S. Problems of methodology in development and modernization of economy. Ekonomicheskie nauki = Economic Sciences, 2015, no. 1 (122), pp. 11-14. (In Russian).

11. Fakhrutdinova E., Mokichev S. Building and development of a new concept in methodology of economic theory. Ekonomicheskie nauki=Economic Sciences, 2013, no. 6 (103), pp. 29-33. (In Russian).

12. Shumpeter J. A. History of economic analysis. Vienna, Springer Verlag, 1986. 908 p. (Russ. ed.: Shumpeter J. A. Istoriya ekonomicheskogo analiza. Saint Petersburg, Ekonomicheskaya Shkola Publ., 2001. Vol. 1-3).

13. Eggertsson T. Economic Behavior and Institutions. Cambridge University Press, 1990. 404 p. (Russ. ed.: Eggertson T. Ekonomicheskoe povedenie i instituty. Moscow, Delo Publ., 2001. 408 p.).

14. Kirman A. The Intrinsic Limits of Modern Economic Theory: The Emperor Has No Clothes. Economic Journal, 1989, vol. 99, no. 395, pp. 126-139.

15. Lowson T. A Realist Perspective on Contemporary «Economic Theory». Journal of Economic Issues, 1995, vol. 29, no. 1, pp. 1-32.

16. Nort D. C. Five propositions about Institutional Change. In Knight J., Sened I. (eds). Sened Explaining Social Institutions. University of Michigan Press, 1995, pp. 15-26.

17. Solow R. Economics: Is Something Missing? Economic History and the Modern Economist. Oxford, Basil Blackwell, 1986, pp. 24-25.

\section{Информация об авторе}

Огородникова Татьяна Владимировна - доктор экономических наук, доцент, декан факультета экономики предприятия и управления бизнесом, Байкальский государственный университет, 664003, г. Иркутск, ул. Ленина, 11, e-mail: ogort@mail.ru.

\section{Author}

Tatyana V. Ogorodnikova - Doctor habil. (Economics), Assistant Professor, Dean of Department of Business Economy and Business Management, Baikal State University, 11 Lenin St., 664002, Irkutsk, Russian Federation; e-mail: ogort@mail.ru.

\section{Библиографическое описание статьи}

Огородникова Т. В. Нелинейные волновые представления в ортодоксальной экономической теории / Т. В. Огородникова // Baikal Research Journal. - 2016. - T. 7, № 3. - DOI : 10.17150/2411-6262.2016.7(3).1.

\section{Reference to article}

Ogorodnikova T. V. Non-linear wave presentation in orthodox economic theory. Baikal Research Journal, 2016, vol. 7, no. 3. DOI : 10.17150/2411-6262.2016.7(3).1. (In Russian).

\section{Baikal Research Journal}

